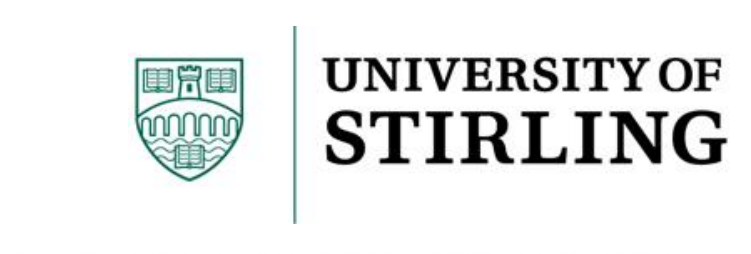

Stirling Management School

\title{
Overtime Working and Contract Efficiency
}

Robert A Hart

Yue Ma

Stirling Economics Discussion Paper 2013-07

May 2013

Online at

http://www.management.stir.ac.uk/research/economics/workingpapers 


\title{
Overtime Working and Contract Efficiency
}

\author{
ROBERT A HART \\ Division of Economics, \\ University of Stirling, \\ Stirling FK9 4LA, \\ Scotland, UK \\ (e-mail: r.a.hart@stir.ac.uk)
}

\author{
YUE MA \\ Department of Economics and Finance, \\ City University of Hong Kong, \\ Hong Kong \\ (e-mail:yue.ma@cityu.edu.hk)
}

May, 2013

\section{ABSTRACT:}

We present a wage-hours contract designed to minimize costly turnover given investments in specific training combined with firm and worker information asymmetries. It may be optimal for the parties to work 'long hours' remunerated at premium rates for guaranteed overtime hours. Based on British plant and machine operatives, we test three predictions. First, trained workers with longer tenure are more likely to work overtime. Second, hourly overtime pay exceeds the value of marginal product while the basic hourly wage is less than the value of marginal product. Third, the basic hourly wage is negatively related to the overtime premium.

KEYWORDS: Paid overtime, wage-hours contract, plant and machine operatives JEL CLASSIFICATION NUMBERS: J41, J33 


\section{Introduction}

Efficient long-term contracts must set hours of work as well as wages (Lazear, 1981; Kahn and Lang, 1992). For most workers, the wage rate and the number of hours are set such that the hourly wage is constant over all per period hours. For an important sub-set of workers, however, marginal hours are remunerated at premium overtime rates. What is the rationale for setting two rates $-a$ basic rate and a premium rate - in terms of contract efficiency? Extending a wage contract structure proposed by Carmichael (1983), designed to minimize costly turnover given sunk investments in specific capital as well as information asymmetries, Hart and Ma (2010) develop a wagehours contract explanation which recognises that it may be optimal for the bargaining parties to agree a contract designed to encourage long hours of work. It establishes the need to pay a premium in excess of basic rates for overtime hours.

Our wage-hours contract offers an alternative derivation of the negative wagepremium trade-off established in earlier work. The best known is the hedonic wage model of Lewis (1969). It describes the 'market equalising wage curve' that reflects the preference of employees and employers who are brought together in equilibrium with labor demand equal to labor supply at all job (i.e. hours) lengths. In essence, the parties agree compensation packages based the worker's objective of finding earnings/hours combinations that maximise utility coupled with the firm's objective of profit maximisation (see Kinoshita, 1987; Trejo, 1991).

After setting out the basic model, we undertake empirical work based on longitudinal panel data in respect of British blue-collar plant and machine operatives. 
This is a relatively homogeneous occupational group in which the incidence of working paid overtime is high. Unlike the United States, there is no regulation on the overtime premium in Britain. We explore three predicted outcomes from the wage-hours contract. First, overtime firms have an incentive to guarantee an overtime premium for extra hours undertaken by trained workers with relatively long job tenure. Second, contract efficiency dictates that the overtime premium is set such that hourly overtime pay exceeds the value of marginal product while the basic hourly wage is less than the value of marginal product. Third, the wage-hours contract contains a compensating rule in which the basic contractual wage is negatively related to the overtime premium.

\section{Overtime working and an efficient wage-hours contract}

We outline the essential features of our wage-hours contract model. Full technical details can be found in Hart and Ma (2010). Following a contract design originally proposed by Hashimoto (1981) and Carmichael (1983), the contract incorporates informational asymmetries between the bargaining parties. There are transaction costs of verifying and communicating information in respect of the value of the marginal product $(V M P)$ and the alternative hourly wage $\left(w_{a}\right)$. We assume that the firm observes $V M P$ and the worker observes $w_{a}$. The firm and the marginal worker negotiate a job contract at the beginning of period 1 and there is no subsequent renegotiation. The contract contains an agreed value of investment return. For example, it may be simple to verify some of the elements that signal the level of productivity, such as the state of current and future orders for the firm's product. 
However, transaction costs preclude ex post agreement over the way in which random elements produce deviations from the agreed value (Hashimoto and $\mathrm{Yu}, 1980$ ).

The marginal worker's pre-entry endowment of general human capital is worth $w_{a}$ in the spot market and this is not augmented within the firm. Specific job training is undertaken at a fixed (i.e. hours-independent) weekly cost. In period 1, the worker has hourly productivity $V M P_{1}$ equal to $w_{a}$ minus the hourly training cost. At the start of period 2 the worker is fully trained, with productivity $V M P_{2}$, and no further training takes place. First and second period hourly wages are denoted $w_{1}$ and $w_{2}$, respectively. Weekly hours in the firm are denoted by $h$ and in alternative employment by $h_{a}$. Weekly earnings net of the disutility of providing weekly hours are expressed $y=w \cdot h-d(h)$. For simplicity, $V M P_{2}$ is constant and invariant with respect to working hours. ${ }^{1}$

As a convenient starting point, suppose the firm and its workforce set fixed standard weekly hours based on custom and practice. The resulting second-period weekly earnings are given by $w_{2} \cdot h_{2}$. The first-best separation rule is given by $w_{a} \cdot h_{a}$ $d\left(h_{a}\right)>V M P_{2} \cdot h_{2}-d\left(h_{2}\right)$. However, the worker would quit if $w_{a} \cdot h_{a}-d\left(h_{a}\right)>w_{2} \cdot h_{2}-d\left(h_{2}\right)$ and the firm would layoff the worker if $w_{2} \cdot h_{2}>V M P_{2} \cdot h_{2}$. Due to asymmetric information combined with no permitted contract renegotiation, such quit/layoff rules allow the possibilities of inefficient separations. An inefficient quit would occur if

(1) $V M P_{2} \cdot h_{2}-d\left(h_{2}\right)>w_{a} \cdot h_{a}-d\left(h_{a}\right)>w_{2} \cdot h_{2}-d\left(h_{2}\right)$

\footnotetext{
${ }^{1}$ The assumption that $V M P_{2}$ declines in hours does not substantively change the main conclusions (Hart and Ma, 2010).
} 
or the worker would quit the firm despite a positive (joint) surplus. An inefficient layoff would occur if

(2) $w_{2} \cdot h_{2}-d\left(h_{2}\right)>V M P_{2} \cdot h_{2}-d\left(h_{2}\right)>w_{a} \cdot h_{a}-d\left(h_{a}\right)$

or the firm would fire the worker despite a positive (joint) surplus.

What if the firm and its workforce agreed to move away from setting hours through custom and practice? As long as a given worker's return $y_{2}=w_{2} \cdot h_{2}-d\left(h_{2}\right)$ increases with $h_{2}$ [i.e. $w_{2}>d^{\prime}\left(h_{2}\right)$ ], then longer hours increase the return and hence induce a greater incentive for the worker to stay. Assuming $w_{2}>d^{\prime}\left(h_{2}\right)$, some marginal workers for whom $w_{a} \cdot h_{a}-d\left(h_{a}\right)>w_{2} \cdot h_{2}-d\left(h_{2}\right)$ held before the increase in $h_{2}$ would now be induced to stay by a reversal of this inequality. As for the firm, increasing $h_{2}$ involves a cost (weekly earnings are increased) and a gain (weekly marginal product is increased). As long as $V M P_{2} \cdot h_{2} \geq w_{2} \cdot h_{2}$ the firm has no incentive to fire. In fact, given the assumption that $V M P^{\prime}\left(h_{2}\right) \equiv 0$, a change in $h_{2}$ has no effect on layoffs. Increases in $h_{2}$ would occur up to the point where $y_{2}=w_{2} \cdot h_{2}-d\left(h_{2}\right)$ is maximized for the marginal worker subject to the constraint that $w_{2} \cdot h_{2} \leq V M P_{2} \cdot h_{2}$. Let the optimal hours for this worker be denoted $h_{o}$.

Operating under a $\left(w_{2}, h_{o}\right)$ wage-hours contract does not rule out the possibility that $V M P_{2}>w_{2}$, in which case the firm would prefer longer hours $h_{2}>h_{0}$. This possibility is precluded in the contract as it stands because hours in excess of $h_{0}$ would reduce $y_{2}$, or

(3) $w_{2} \cdot h_{2}-d\left(h_{2}\right)<w_{2} \cdot h_{0}-d\left(h_{0}\right)$ for $h_{2}>h_{0}$ 
implying that the probability that the worker quits is increased thereby increasing the likelihood of an inefficient separation.

One possibility of compensating the fall of $y_{2}$ for a rise in $h_{2}$ beyond $h_{0}$, is for the firm to offer overtime pay k. $w_{2}$ in respect of marginal hours such that $w_{2} \cdot h_{0}+k \cdot w_{2} \cdot\left(h_{2}-\right.$ $\left.h_{o}\right)-d\left(h_{2}\right)>w_{2} \cdot h_{o}-d\left(h_{o}\right)$. Using inequality (3), this implies that the overtime premium $k$ would be set such that

(4) $k>\frac{d\left(h_{2}\right)-d\left(h_{0}\right)}{w_{2} \cdot\left(h_{2}-h_{0}\right)}>1$.

The firm pays an overtime premium $k>1$ to compensate the worker for the disutility of 'involuntary' long hours.

The problem arises that the firm cannot pay all, equally productive, trained workers $k_{2} \cdot w_{2}\left(k_{2}>1\right)$. This would increase marginal pay and hence increase the probability of layoffs. As things stand, the cost of retaining the marginal worker in period 2 is equal to the pay of a marginal worker. However, greater contract efficiency can still be achieved using premium overtime pay via a solution equivalent to the wage contract proposed by Carmichael (1983). This translates into creating junior and senior jobs for equally trained workers. Junior workers work $h_{0}$ hours at a single rate of $w_{2}$ while a fixed number of senior workers are guaranteed additional overtime hours at a premium rate, $k \cdot w_{2}$. Eventually, as a senior worker retires or leaves the firm for other reasons, it becomes the turn of a junior worker to be offered the additional premiumrated hours. Total employment is secured through a senior worker being replaced by a junior worker at cost $w_{2}$. The firm's marginal hourly cost is $k \cdot w_{2}$ while the marginal 
hourly replacement cost is $w_{2}$. Efficiency is achieved because the cost of retaining a marginal worker differs from the pay of a marginal worker.

What is the incentive for workers to agree to such an arrangement? It turns out that this overtime pay scheme has the automatic compensating rule

(5) $k \cdot w_{2}>V M P_{2}>w_{2}$

that reduces both inefficient quits and inefficient layoffs (Hart and Ma, 2010). The incentive is to receive a wage for marginal hours that exceeds the value of the marginal product. Figure 1 illustrates the overtime pay schematic resulting from these developments.

What is the relationship between the contractual wage and the overtime premium in our wage-hours contract? There is an inverse relationship, or (6) $\frac{\partial w_{2}}{\partial k}<0$.

Lowering $w_{2}$ increases profit to the firm but also increases the probability of the worker quitting. Hence the wage stopping rule is where the marginal profit to the firm equals to marginal loss of an extra unit reduction of $w_{2}$. Similarly, an increase of $k$ reduces the profit to the firm but increases the probability of the worker staying, which in turn enhances the firm's profit. Hence the premium stopping rule is where the marginal loss to the firm equals to marginal profit of an extra unit increase of $k$.

In our empirical work, a potential complication to the foregoing theoretical discussion arises if the senior overtime job involves significantly different job tasks from 
the junior job. To the extent that specific capital derives from task-specific training (see Gibbons and Waldman 2004), such an internal job change would involve investment write-offs that would run against the rationale of the efficient contract structure. As acknowledged by Carmichael (1983), the initial training programme would need to produce workers being equally capable of doing the junior and the senior job and, moreover, numbers of workers in junior and senior jobs would need to be set such that marginal product of a worker in each type of job is the same. We tackle this issue empirically in two ways. First, we concentrate on plant and machine operatives. It is more likely that job promotions within this reasonably narrow range of associated blue collar job descriptions would involve quite major overlaps in job tasks thereby making initial training quite relevant to both junior and senior jobs. Second, job tenure in our British individual longitudinal data is defined at 3-digit occupation level. Where an internal job move involves a change in job tasks sufficient to warrant a new 3-digit heading then this marks the start of a new period of tenure. Since we concentrate on job tenure only within single 3-digit occupations we rule out the problem of major changes in job descriptions and associated job tasks.

\section{Empirical Tests}

The foregoing model leads to three predictions concerning overtime working. First, paid overtime is undertaken by senior trained workers in the firm. Second, overtime premium pay is greater than the value of marginal product which in turn is greater than the basic wage or $k \cdot w_{2}>V M P_{2}>w_{2}$. Third, there is an inverse relationship between $w_{2}$ and $k$. 
Consistent with our first prediction, we would expect that the probability of working paid overtime to be positively related to the length of job tenure. For exposition, we concentrate on linear terms in tenure $(T E N)$ and age $(A G E){ }^{2}$ Tenure refers to job tenure defined as the period of time working within a single 3-digit occupation in a given firm.

Let

(7) $\quad O V_{i t}=1$ if worker $i$ at time $t$ is working paid overtime

$O V_{i t}=0$ otherwise.

In order to accommodate the likely procyclicality of $O V_{i t}$, we include as an explanatory variable the annual change in the national unemployment rate to capture business fluctuations. This requires us to tackle potential standard error biases associated with using an individual-level dependent variable alongside a national-level cyclical indicator. To this end, we adopt the two-step estimation approach first proposed by Solon et al. (1994).

Step 1 estimation is given by

(8) $O V_{i t}=\alpha_{1} T E N_{i t}+\alpha_{2} A G E_{i t}+\alpha_{3} B A R_{i t}+\sum_{t=1}^{T} \theta_{t} D_{t}+I_{i t} \mu+\varepsilon_{i t}$ where $B A R_{i t}$ is a dummy denoting an individual's job is covered by collective bargaining, $D_{t}$ is a year dummy, and $l_{i t}$ is a set of industry dummies. From our theory, we expect

\footnotetext{
${ }^{2}$ Our data set most suited for this estimation - the British New Earnings Survey Panel Data (NESPD) - do not allow the calculation of work experience and so we use the individual's age in its place.
} 
$\hat{\alpha}_{1}>0$. We also expect $\hat{\alpha}_{3}>0$ or contractual overtime is positively related to jobs in which collective bargaining takes place.

Step 2 estimation is given by (9) $\hat{\theta}_{t}=\beta_{0}+\beta_{1} \Delta U_{t}+\beta_{2}$ Year $_{t}+\omega_{t}$ where $\Delta U_{t}$ is first-differenced national claimant count unemployment and Year $r_{t}$ is a simple time trend. In order to facilitate use of the two-step method, we estimate (9) as a linear probability model using weighted least squares where weights consist of the number of individuals observed in each year. We expect $\hat{\beta}_{1}<0$ since the probability of working overtime rises towards cyclical peaks and declines near troughs. ${ }^{3}$

In the case of the second prediction, that $k \cdot w>V M P>w_{2}$, we offer two tests.

If, as our theory supports, overtime is remunerated under efficient contracts at a rate higher than VMP then we would expect lower job separation probabilities for this class of worker. Given capital specificity, workers may find it difficult to obtain alternative employment that matches their marginal rates of pay.

Let $S_{i t}$ denote a binary variable such that

$$
\begin{aligned}
& S_{i t}=1 \text { if worker } i \text { separates from his job at time } t \\
& S_{i t}=0 \text { otherwise. }
\end{aligned}
$$

Then, following the same empirical approach as before, we specify a linear probability model such that

\footnotetext{
${ }^{3}$ We also estimated a probit model incorporating clustering for the unemployment variable. This yielded marginal effects similar to our 2-step approach.
} 
(11) $S_{i t}=\gamma_{1} A G E_{i t}+\gamma_{2} O V_{i t-1}+\gamma_{3} B A R_{i t}+\sum_{t=1}^{T} \varphi_{t} D_{t}+I_{i t} \tau+\varepsilon_{i t}$

where $O V_{i t-1}=1$ if the worker worked overtime in the previous period. Note that $T E N_{i t}=$ 0 at points of separation. We expect $\hat{\gamma}_{1}<0$ given younger workers display more job mobility than older workers (e.g. Macaulay, 2003). As discussed above, we expect $\hat{\gamma}_{2}<0$. We also expect that $\hat{\gamma}_{3}<0$ or there is a reduced probability of separation in jobs covered by collective bargaining.

Step 2 estimation is given by

(12) $\hat{\varphi}_{t}=\delta_{0}+\delta_{1} \Delta U_{t}+\delta_{1} Y_{e a r_{t}}+\omega_{t}$

where we expect $\hat{\delta}_{1}<0$, or separations are procyclical. ${ }^{4}$

The difficulty with formulating a more direct test of the inequalities in (5) - viz. $k . w_{2}>V M P_{2}>w_{2}-$ is that we require measures of individual productivities. Such variables are not available in our British data sources. However, a modelling approach introduced by Kahn and Lang (1992) - who test for the relative strengths of agency versus human capital theories in predicting long term associations between the wage and $V M P$ - gives us a way to proceed.

Assuming job tenure captures the accumulated productive returns on-the-job, after controlling for general labor market work experience, three relationships are of interest.

\footnotetext{
${ }^{4}$ Again, a probit allowing for marginal effects and clustering in respect of unemployment produced similar outcomes.
} 
(13) $\ln w_{i t}=\lambda_{1} T E N_{i t}+Z_{i t} \Gamma_{1}+\varepsilon_{1 i t}$,

(14) $\ln V M P_{i t}=\lambda_{2} T E N_{i t}+Z_{i t} \Gamma_{2}+\varepsilon_{2 i t}$,

(15) $\ln (k \cdot w)_{i t}=\lambda_{3} T E N_{i t}+Z_{i t} \Gamma_{3}+\varepsilon_{3 i t}$,

where $Z$ is a set of controls and where we expect, given (5), that $\lambda_{1}<\lambda_{2}<\lambda_{3}$ (see Figure $1)^{5}$

The probability that desired hours exceed contact hours is the probability that the hourly wage (standard or overtime) exceeds VMP. This is expressed

(16) $\operatorname{Pr}[$ desired hours $>$ contract hours $]=$

$$
\operatorname{Pr}\left[\left(1-O V_{i t}\right) \cdot \ln w_{i t}+O V_{i t} \cdot \ln (k \cdot w)_{i t}\right]>\ln V M P_{i t}
$$

If $O V=1$ then $k \cdot w>V M P$ and workers will desire more hours. If $O V=0, w<V M P$ and less hours would be desired. Using (13), (14) and (15), we can re-write equation (16) as

(17) $\operatorname{Pr}[$ desired hours $>$ contract hours $]=$

$$
\begin{gathered}
\operatorname{Pr}\left[Z_{i t}\left(\Gamma_{1}-\Gamma_{2}\right)+O V_{i t} \cdot Z_{i t}\left(\Gamma_{3}-\Gamma_{1}\right)+\left(\lambda_{1}-\lambda_{2}\right) \cdot T E N_{i t}+\left(\lambda_{3}-\lambda_{1}\right) O V_{i t} \cdot T E N_{i t}\right. \\
\left.+\left(1-O V_{i t}\right) \varepsilon_{1 i t}+O V_{i t} \varepsilon_{3 i t}-\varepsilon_{2 i t}>0\right] .
\end{gathered}
$$

\footnotetext{
${ }^{5}$ Equations (13) - (15) are estimated using the British Household Panel Dataset (BHPS) since, unlike the NESPD, this data source provides information on workers' desired hours (see the Appendix for discussion). It also allows us to measure work experience (EXP) - given by the number of years in the workforce since the end of full-time education - and this replaces AGE in the relevant regressions.
} 
Providing that the error terms are normally distributed, then (17) can be estimated as a bivariate probit equation. Our theory predicts that (i) the coefficient on tenure should be negative, (ii) the coefficient on OV.TEN should be positive, and (iii) the sum of these coefficients should be positive. Finally, $\left(\Gamma_{1}-\Gamma_{2}\right)$ and $\left(\Gamma_{3}-\Gamma_{1}\right)$ can be any sign for $Z$ and for OV.Z, respectively.

However, there is a problem with estimating (17) as a simple probit. From Table 1, we find that over half of respondents in our BHPS sample report that they are satisfied with their actual hours. This same problem is found by Kahn and Lang (1992) in their work on agency versus specific capital. They suggest two model modifications to accommodate the problem. Equivalent lines of reasoning apply here.

The first modification is to assume that respondents report an inequality between actual and desired hours only if the deviations are nontrivial. Then we can define a dummy taking the value 1 for a sufficiently large positive deviation, -1 for a sufficiently large negative deviation, and 0 for deviations that do not trigger either of these responses. Then equation (17) can be estimated as an ordered probit.

The second modification concerns the fact that the overtime model outlined here is most relevant to long-term employment relationships that incorporate the objective of minimising quits and layoffs given potential losses of returns to specific capital investments. In effect, our model treats overtime as a guaranteed payment. But we know that paid overtime arises for a range of other, often more ad hoc and shortterm, reasons. The firm may employ overtime hours to meet rush orders, to fill the gap of a temporary shortfall of labor given unanticipated rises in product demand, to 
provide cover for absenteeism, and so on. So the inequality arising from the structural assumptions behind equation (17) might reasonably be taken to be conditional on an expected long-term employer-worker relationship. A simple bivariate probit is then interpreted as capturing workers who are constrained in this way.

We might also expect that longer term contractual hours arrangements are more likely to apply to experienced, prime-age, workers. For many workers, job shopping in early years in the labor market will result in improved job matches that eventually give the parties more confidence in investing in longer term relationships. Older workers who, for whatever reason, have changed jobs may be less likely to receive significant new job opportunities given shorter expected time horizons in which to amortize investment outlays in training. Accordingly, we carry out estimation both with respect to all plant and machine operatives and those aged between 25 to 45 years. Age distributions of plant and machine operatives over the period 1991-2011 are shown in Figure 2, covering all workers as well the sub-set working overtime. The two distributions are almost identical. Of all observations, 55\% are within the 25-45 age range.

The last prediction from the theory is that $\partial k / \partial w<0$, or the overtime premium and the hourly standard wage are inversely related. The NESPD provides data on total weekly hours $(H)$, standard weekly hours $(H S)$, weekly overtime hours $H P(=H-H S)$ as well as hourly earnings including overtime $(e)$ and the standard hourly wage $(w)$. Then, for each worker, the average overtime premium, $p$, is given by 
(18) $p_{i t}=\frac{\left(\frac{e_{i t}}{w_{i t}}\right) H_{i t}-H S_{i t}}{H P_{i t}}$.

where $p_{i t}>0$ if $H_{i t}>H S_{i t}$, and $p_{i t}=0$ if $H_{i t} \leq H S_{i t}$.

We investigate the wage-premium trade-off via the wage equation

$$
\log w_{i t}=\pi_{1} p_{i t}+\pi_{2} T E N_{i t}+\pi_{3} A G E_{i t}+\gamma_{4} B A R_{i t}+Z_{i t} \Omega+\varepsilon_{i t}
$$

where $\log w_{i t}$ is the log of the real basic wage rate (excluding overtime) and where $Z_{i t}$ are controls consisting of time and industry dummies. We expect $\hat{\pi}_{1}<0$ from the theory. We estimate (19) by OLS as well as by controlling for individual fixed effects.

\section{Data}

Our estimation is carried out using data on British plant and machine operatives reported in the NESPD (British New Earnings Survey Panel Data) and the BHPS (British Household Panel Dataset). These consist of a relatively homogeneous group of bluecollar occupations. ${ }^{6}$ Britain's best statistical source for pay and hours is the companybased NESPD. We make use of this data set from 1991 to 2011. However, the NESPD does not ask questions concerning individuals' desired working time and so we use the household-based BHPS in this respect. These data are available from 1991 to 2008. The comparative advantage of NESPD is its large sample coverage and accuracy. It is based

\footnotetext{
${ }^{6}$ The NESPD's coverage of plant and machine operatives embraces over sixty-two 3-digit occupations. These are grouped by process operatives (food drink and tobacco; textile and tannery; chemicals, paper, plastics and related; metal making and treating; metal working; other routine) and by other work (assemblers/lineworkers; road transport; other transport and machinery; plant and machine).
} 
on company payroll records and, unlike the BHPS, it does not rely on self reporting. The comparative advantage of the BHPS is that it allows for a wider set of controls, including household and educational background. For both our data sets, Table 1 shows that over half of individuals/households covered by our plant and machine operators' samples report working paid overtime.

The complete NESPD is comprised of a random sample of $1 \%$ of the entire British workforce. Employers complete a questionnaire, based on their payrolls, that relates to a specific week in April. Since the same individuals are in the sample each year, the NESPD is a panel data set. Completing the survey questionnaire is a legal requirement and so the response rate is very high. Since the data are taken directly from the employer's payroll records, the earnings and hours information in the NESPD are considered to be very accurate. A question in the Survey allows us to identify job movers and so we can accurately measure spell lengths of 3-digit level jobs.

The BHPS is an annual survey consisting of a nationally representative sample of about 5,500 households recruited in 1991 and containing a total of approximately 10,000 interviewed individuals in Great Britain. In 1999, additional samples were added consisting of 1,500 households in each of England and Wales. The sample is a stratified clustered design drawn from the Postcode Address File and all residents present at those addresses at the first wave of the survey were designated as panel members. These same individuals are re-interviewed each successive year and, if they split-off from original households to form new households, they are followed and all adult 
members of these households are also interviewed. Similarly, new members joining sample households become eligible for interview.

One downside of the BHPS data should be mentioned. In contrast to the NESPD, tenure in the BHPS refers to length of stay in the firm rather than stay within given occupations in the firm. This is clear when comparing lengths of tenure in the two data sets reported in Table $1 .^{7}$ So changes in tenure in the BHPS may involve job promotions that are not accommodated by the assumptions behind our efficient contract design.

From Table 1 we find that standard weekly hours of plant and machine operatives are comparable in the data sets, averaging about 40 hours per week. Overtime hours of plant and machine operatives are high, averaging around 10/11 weekly hours for those working overtime and around 5/6 hours over all operatives. Average real weekly earnings in the NESPD and BHPS, including overtime pay, compare closely. The average overtime premium is 1.4 in both surveys. ${ }^{8}$

\footnotetext{
${ }^{7}$ Even given the distinction between job tenure and employer tenure, the differences in average tenure lengths - about 2.8 years in the NESPD compared with 5.5 years in the BHPS - appear too large. This arises because interviewees in the BHPS are asked when they started with the current firm and this is recorded as the tenure starting point even if they are first recorded at a later stage. No such retrospective question is asked in the NESPD and this accentuates the tenure gaps between the two panel surveys.

${ }^{8}$ Note that this is an average across weekly overtime hours of the individual. The marginal rate may be higher. For example, some individuals may work during weekends or holiday periods at higher premium rates. There is quite strong British evidence, however, that the overtime premium does not vary by length of overtime hours (Bell and Hart, 2003).
} 


\section{Results}

Within 3-digit level jobs, we obtain evidence in Table 2 in support of the prediction that the probability of working paid overtime increases with job tenure. In Section 2, we argue that the NESPD jobs-based data provide a strong test of the proposed contract model because we can control against more senior workers undertaking more overtime due to major changes in job descriptions within the firm. We note also from Table 2 that the probability of undertaking paid overtime, controlling for job tenure, rises in age. Figure 2 shows that the incidence of overtime working peaks among individuals in their middle 20 s to middle 40 s. We find that the probability of overtime working is positively related to jobs in which collective bargaining takes place, a result compatible with our wage-hours contract formulation. Finally, and unsurprisingly, the probability of working overtime is found to be strongly procyclical.

Our model provides an incentive to work long hours by paying hourly contract wages for all trained workers below marginal product and hourly overtime pay for longer tenured workers above marginal product. Under such an incentive structure we would expect that this would serve to reduce the probability of job separation among overtime workers. This expected outcome is supported by our results in Table 3 . The probability of separations in a given time period is significantly lower among workers who worked overtime in the previous period. Age is also negatively related to job separations, which is a well known result in the literature. Younger workers generally display more job mobility than older workers (e.g. Macaulay, 2003). Job separations are found to be less likely to feature in jobs that are subject to collective bargaining 
agreements, a result plausibly linked to an implied great security of employment. At best, we find that the probability of job separations among plant and machine operatives is weakly procyclical.

Table 4 contains the BHPS estimates that are designed to test if our modelling outcomes are consistent with the overtime schematic portrayed in Figure 1, with $k \cdot w_{2}>$ $V M P_{2}>w_{2}$. As discussed earlier, we show estimates based on both ordered and simple probits. If these inequalities hold then the prediction is, via equation (17), that the probability desired hours exceed actual hours should correlate (i) negatively with tenure, (ii) positively with tenure interacted with working overtime, and (iii) positively over the sum of these two effects. We argue in Section 3 that there is reason to test the underlying empirical model in respect of all operatives (aged 16 to 65) and prime age operatives (25-45). All three predicted signs hold for both age ranges. However, statistically, the restriction in (iii) is supported by a Wald test only in respect of the narrower age sample.

We plotted the average real hourly wage rates (excluding overtime) associated with estimated average premiums rising in steps of 0.05 in the range 1.0 to 2.0. Outcomes in respect of all operatives are shown in Figure 3. For most of the range the relationship is strongly negative. Only at very high average premiums - in excess of 1.55 - does the relationship cease to hold. Only $11.7 \%$ of overtime workers receive an average premium higher than 1.55. In line with this evidence, our wage regression estimates of equations (19), shown in Table 5, support a significantly negative wagepremium relationship. While individual fixed effects coefficient estimates are somewhat 
smaller than their OLS equivalents, the estimation methods provide reasonably comparable outcomes.

\section{Conclusion}

Given specific training investment combined with information asymmetries, we view premium-paid overtime working as providing a means of the firm and its workers achieving mutual benefits from working long hours. Where work schedules beyond the standard workday are considered to be potentially profitable, then paying for overtime hours above marginal product to senior trained workers and standard hours below marginal product to all trained workers provides a more efficient contractual outcome than the payment of a single hourly wage rate. Despite other motives for working paid overtime, such as to meet short-term unforeseen bottlenecks, our proposed model gains support from evidence based on British plant and machine operatives. 


\section{References}

Altonji, Joseph G., and Robert A. Shakotko. 1987. Do wages rise with job seniority? Review of Economic Studies 54: 437-59.

Bell, David N.F., and Robert A. Hart. 2003. Wages, hours, and overtime premia: evidence from the British labour market. Industrial and Labor Relations Review 56: 470-80. Carmichael, Lorne. 1983. Firm-specific human capital and promotion ladders. Bell Journal of Economics 14: 251-58.

Gibbons, Robert, and Michael Waldman. 2004. Task-specific human capital. American Economic Review Papers and Proceedings 94: 203-07.

Hart, Robert A, and Yue Ma. 2010. Wage-hours contracts, overtime working and premium pay. Labour Economics 17: 170-79.

Hashimoto, Masanori. 1981. Firm-specific human capital as a shared investment. American Economic Review 71: 475-82.

Hashimoto, Masanori and Ben T Yu (1980): Specific capital, employment contracts and wage rigidity, Bell Journal of Economics 11: 536-49.

Kahn, Shulamit, and Kevin Lang. 1992. Constraints on the choice of hours. Journal of Human Resources 27: 661 - 78.

Kinoshita Tomio. 1987. Working hours and hedonic wages in the market equilibrium. Journal of Political Economy 95: 1262-77.

Lazear, Edward P. 1981. Agency, earnings profiles, productivity, and hours restrictions. American Economic Review 71: 606-20.

Lewis, H.Gregg. 1969. Employer interests in employee hours of work. mimeo, University of Chicago.

Macaulay, Claire. 2003. Job mobility and job tenure in the UK. Labour Market Trends, Office for National Statistics: 541-550.

Solon, Gary, Robert Barsky, and Jonathan A. Parker. 1994. Measuring the cyclicality of real wages: how important is composition bias? Quarterly Journal of Economics 109, 126. 
Trejo, Stephen J. 1991. The effects of overtime pay regulation on worker compensation, American Economic Review 81: 719-40. 


\section{Appendix: Desired and actual hours in the BHPS}

The key question asked in the BHPS is: "Thinking about the hours you work, and assuming that you would be paid the same amount per hour, would you prefer to (a) work fewer hours, (b) work more hours, (c) continue with the same hours." 9 How does this question link to our analysis? For a respondent who works no overtime and is remunerated at the basic hourly rate, the interpretation of the question is unambiguous. Consider the response of an overtime worker. In this case, the question arises as to whether the respondent treats the marginal wage as the basic wage or the overtime wage (i.e. the basic rate times the overtime premium). Two possibilities arise. First, an overtime worker regards a desired increase/decrease in hours in terms of a change in overtime hours. This is likely to be the case because basic hours are generally stipulated in British wage contracts to constitute the first hours worked during the working day or week. If overtime is scheduled then overtime hours follow on from the agreed number of basic hours. It follows in this case that an overtime worker would perceive that changing hours at the margin means changing overtime hours. Second, a less likely response among overtime workers may occur if the BHPS question was interpreted as referring to basic hours in relation to basic wage rates. They may then indicate that they would prefer to work fewer basic hours while regarding their overtime hours as unchanged. Thus the BHPS question may result in an underestimation of a positive hours' response.

\footnotetext{
9 Additionally, the survey records 'inapplicable', 'proxy respondent' and 'don't know' responses, which we ignore.
} 
Figure 1 Second-period hourly pay profile

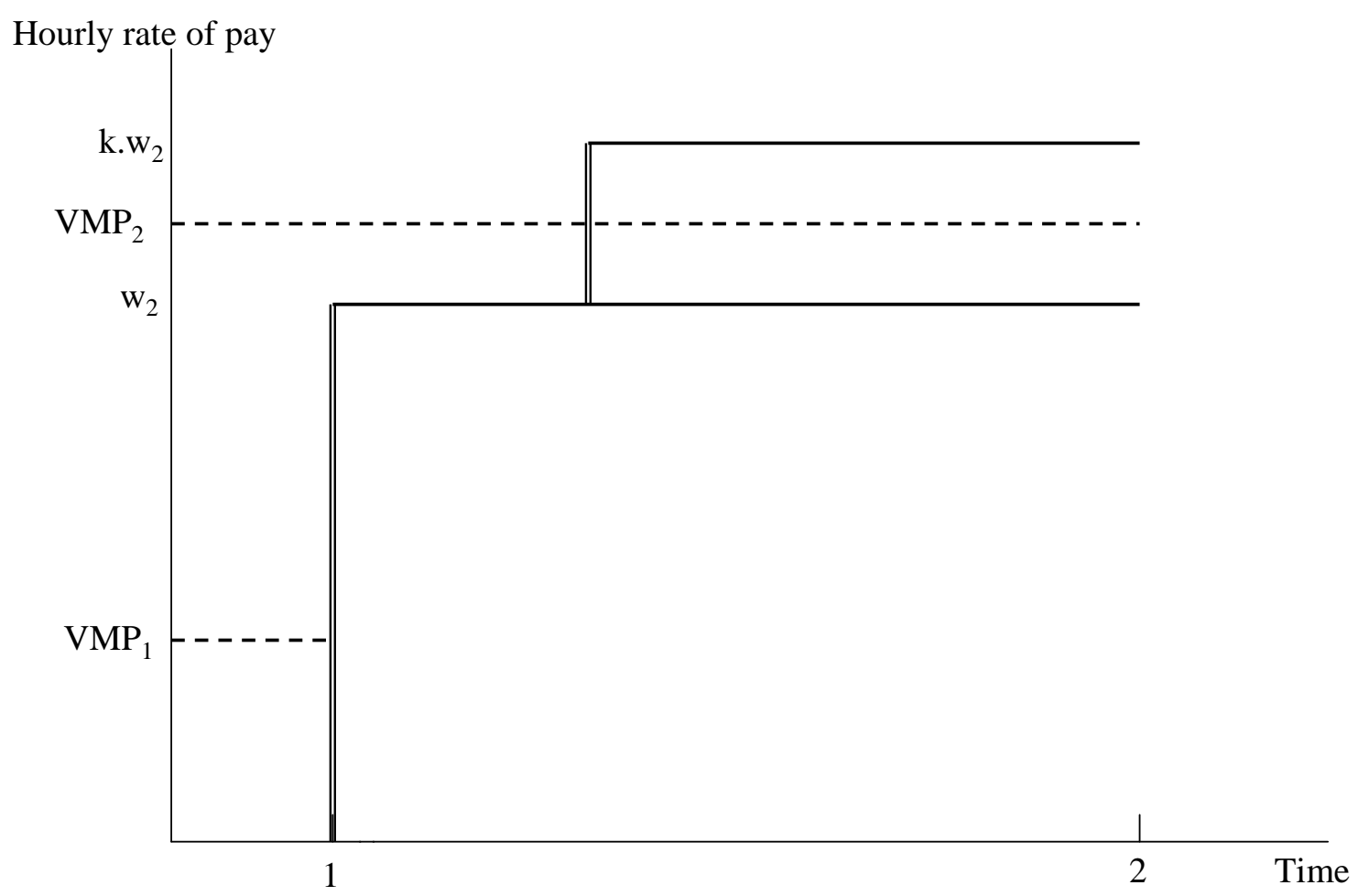


Figure 2 Age distribution of plant and machinery observations: 1991-2011 (NESPD)

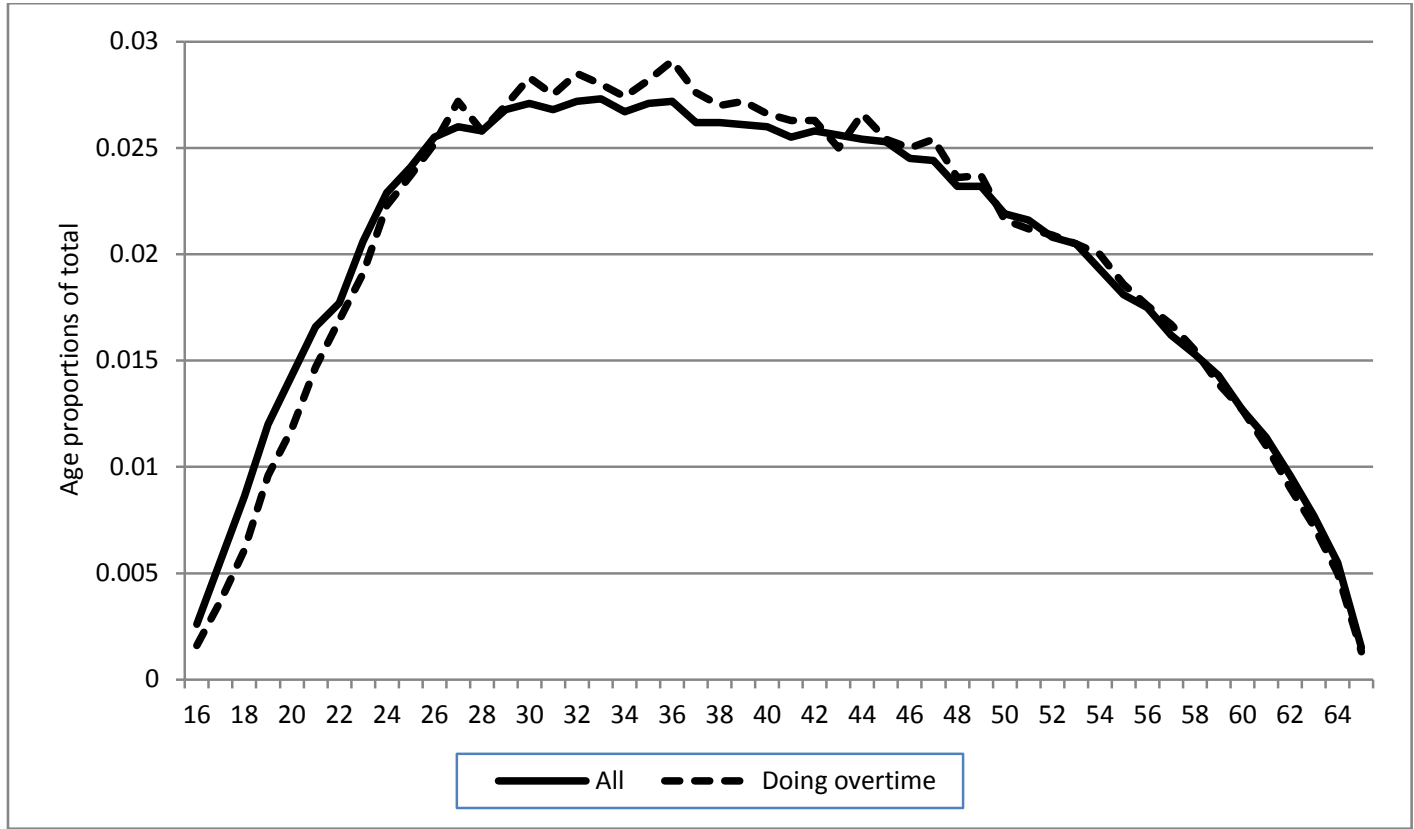

Figure 3 Real basic hourly wages and the overtime premium: plant and machine operatives aged 16-65, 1991-2011 (NESPD)

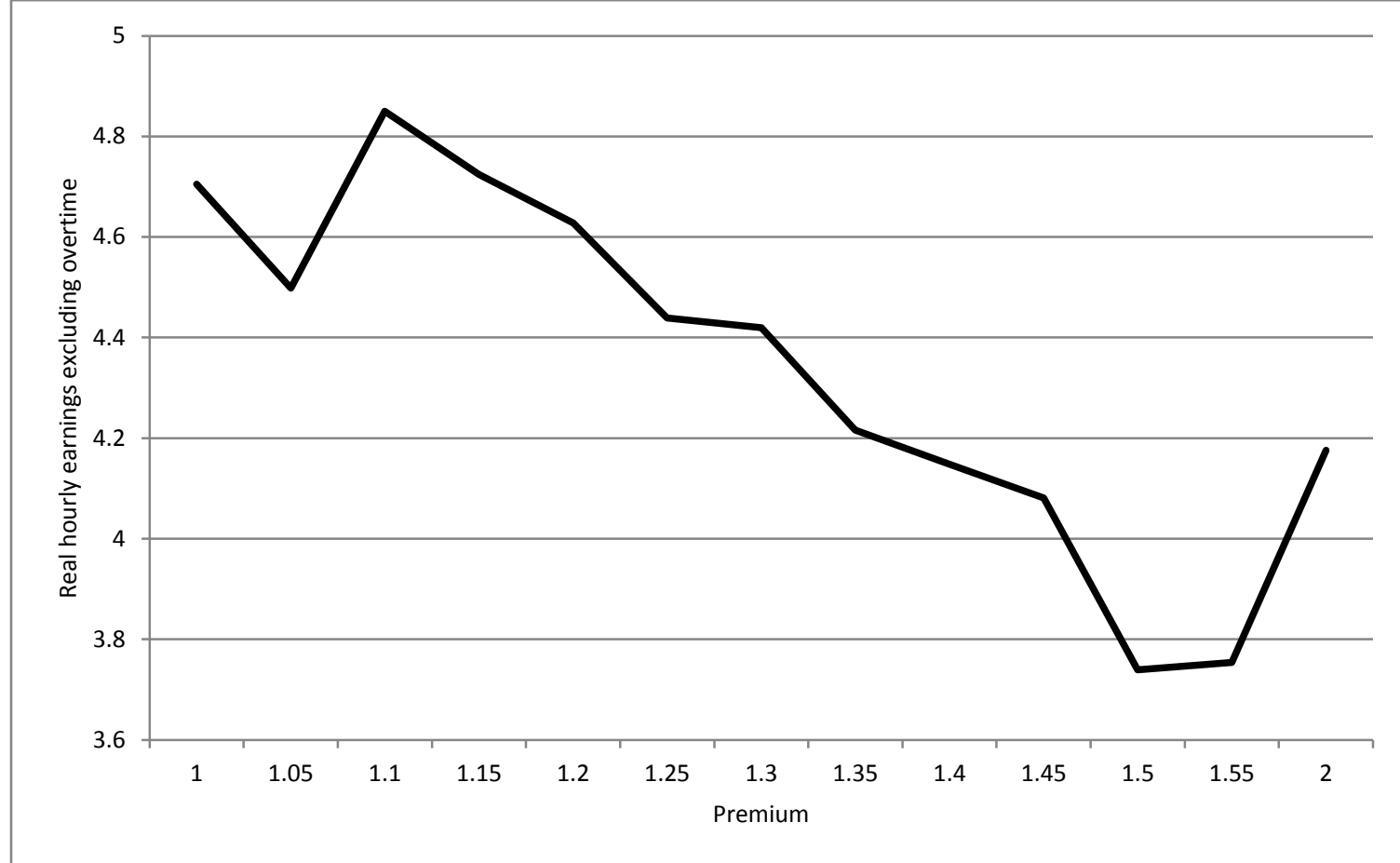


Table 1 Background statistics: plant and machine operatives, NESPD (1991-2011) and BHPS (1991-2008)

\begin{tabular}{|c|c|c|c|}
\hline & \multicolumn{2}{|c|}{ Operatives aged $16-65$} & \multirow{2}{*}{$\frac{\text { Operatives aged 25-45 }}{\text { BHPS }}$} \\
\hline & NESPD & BHPS & \\
\hline Percentage working paid overtime & 54.3 & 53.1 & 54.8 \\
\hline $\begin{array}{l}\text { Standard weekly hours of } \\
\text { overtime workers }\end{array}$ & 39.4 & 40.3 & 40.7 \\
\hline $\begin{array}{l}\text { Standard weekly hours of all } \\
\text { workers }\end{array}$ & 39.4 & 40.4 & 41.0 \\
\hline $\begin{array}{l}\text { Average weekly paid overtime } \\
\text { hours of overtime workers }\end{array}$ & 9.5 & 10.7 & 11.1 \\
\hline $\begin{array}{l}\text { Average weekly paid overtime } \\
\text { hours of all workers }\end{array}$ & 5.2 & 5.7 & 6.1 \\
\hline $\begin{array}{l}\text { Average years of job tenure } \\
\text { (NESPD)/employer tenure (BHPS) } \\
\text { of overtime workers }\end{array}$ & 2.8 & 5.4 & 4.1 \\
\hline $\begin{array}{l}\text { Average years of job tenure } \\
\text { (NESPD)/employer tenure (BHPS) } \\
\text { of all workers }\end{array}$ & 2.8 & 5.5 & 4.4 \\
\hline $\begin{array}{l}\text { Average real weekly earnings of } \\
\left.\text { overtime workers ( } f^{\prime} s\right)\end{array}$ & 222.3 & 212.3 & 222.3 \\
\hline $\begin{array}{l}\text { Average real weekly earnings of all } \\
\text { workers }\left(f^{\prime} s\right)\end{array}$ & 203.5 & 200.9 & 211.6 \\
\hline Average overtime premium & 1.4 & 1.4 & 1.4 \\
\hline $\begin{array}{l}\text { Proportion of total males whose } \\
\text { desired hours }>\text { actual hours }\end{array}$ & - & 6.7 & 7.0 \\
\hline $\begin{array}{l}\text { Proportion of total males whose } \\
\text { desired hours = actual hours }\end{array}$ & - & 56.5 & 56.2 \\
\hline $\begin{array}{l}\text { Proportion of total males whose } \\
\text { desired hours < actual hours }\end{array}$ & - & 36.8 & 36.8 \\
\hline
\end{tabular}


Table 2 OLS estimates of working paid overtime: plant and machine operatives, NESPD, 1991-2011

\begin{tabular}{|c|c|}
\hline & Step1 estimates \\
\hline TENURE & $\begin{array}{c}0.0062 * * \\
(0.0011)\end{array}$ \\
\hline TENURE $^{2} / 100$ & $\begin{array}{c}-0.0447 * * \\
(0.0073)\end{array}$ \\
\hline AGE & $\begin{array}{c}0.0145^{* *} \\
(0.0010)\end{array}$ \\
\hline $\mathrm{AGE}^{2} / 100$ & $\begin{array}{c}-0.0170 * * \\
(0.0013)\end{array}$ \\
\hline COLLECTIVE BARGAINING & $\begin{array}{l}0.0099 * \\
(0.0050)\end{array}$ \\
\hline Industry and year dummies & Yes \\
\hline \multirow[t]{2}{*}{ Sample size } & 74,213 \\
\hline & Step 2 estimate \\
\hline$\Delta$ (UNEMPLOYMENT) & $\begin{array}{c}-0.0161^{* *} \\
(0.0042)\end{array}$ \\
\hline Constant and time trend & Yes \\
\hline Sample size & 21 \\
\hline
\end{tabular}

Notes: Sample: male plant and machine operatives aged 16 to 65 . Bracketed figures are standard errors and $* *(*)$ denotes $1 \%(5 \%)$ significance. 
Table 3 OLS estimates of job separations: plant and machine operatives, NESPD, 1991-2011

\begin{tabular}{|l|c|}
\hline & Step1 estimates \\
\hline WORKED PAID OVERTIME IN PREVIOUS PERIOD & $-0.0137^{* *}$ \\
& $(0.0025)$ \\
AGE $\mathbf{2}$ 100 & $-0.0088^{* *}$ \\
& $(0.0008)$ \\
COLLECTIVE BARGAINING & $0.0073^{* *}$ \\
& $(0.0009)$ \\
\hline Industry and year dummies & -0.0065 \\
\hline Sample size & $(0.0034)$ \\
\hline (UNEMPLOYMENT) (all separations) & Yes \\
\hline Sample size & 51,844 \\
\hline Constant and time trend & Step 2 estimate \\
\hline
\end{tabular}

Notes: Sample: male plant and machine operatives aged 16 to 65 . Bracketed figures are standard errors and $* *(*)$ denotes $1 \%(5 \%)$ significance. 
Table 4 Ordered probit and probit estimates of wanting more versus less hours at the same hourly wage rate: plant and machine operatives, BHPS, 1991-2008

\begin{tabular}{|c|c|c|c|c|}
\hline & \multicolumn{2}{|c|}{ Operatives aged 16-65 } & \multicolumn{2}{|c|}{ Operatives aged $25-45$} \\
\hline & Ordered & $\begin{array}{c}\text { More versus } \\
\text { Less }\end{array}$ & Ordered & $\begin{array}{c}\text { More versus } \\
\text { Less }\end{array}$ \\
\hline TEN & $\begin{array}{c}-0.0100 * * \\
(0.0037)\end{array}$ & $\begin{array}{c}-0.0242 * * \\
(0.0082)\end{array}$ & $\begin{array}{c}-0.0186 * * \\
(0.0062)\end{array}$ & $\begin{array}{c}-0.0426 * * \\
(0.0146)\end{array}$ \\
\hline OV.TEN & $\begin{array}{l}0.0104 * \\
(0.0047)\end{array}$ & $\begin{array}{c}0.0318^{* *} \\
(0.0105)\end{array}$ & $\begin{array}{c}0.0297^{* *} \\
(0.0083)\end{array}$ & $\begin{array}{c}0.0667 * * \\
(0.0183)\end{array}$ \\
\hline EXP & $\begin{array}{c}-0.0310 * * \\
(0.0058)\end{array}$ & $\begin{array}{c}-0.0408^{* *} \\
(0.0120)\end{array}$ & $\begin{array}{l}-0.0178 \\
(0.0202)\end{array}$ & $\begin{array}{c}0.0082 \\
(0.0413)\end{array}$ \\
\hline$(E X P)^{2} / 10$ & $\begin{array}{c}0.0049 * * \\
(0.0011)\end{array}$ & $\begin{array}{l}0.0054^{*} \\
(0.0025)\end{array}$ & $\begin{array}{c}0.0035 \\
(0.0057)\end{array}$ & $\begin{array}{l}-0.0045 \\
(0.0116)\end{array}$ \\
\hline OV.EXP & $\begin{array}{c}-0.0209 * \\
(0.0043)\end{array}$ & $\begin{array}{c}-0.0344 * * \\
(0.0089)\end{array}$ & $\begin{array}{l}-0.0175 \\
(0.0107)\end{array}$ & $\begin{array}{l}-0.0263 \\
(0.0220)\end{array}$ \\
\hline$(\text { OV.EXP) })^{2} / 10$ & $\begin{array}{c}0.0038 * * \\
(0.0011)\end{array}$ & $\begin{array}{c}0.0045 \\
(0.0025)\end{array}$ & $\begin{array}{c}0.0008 \\
(0.0045)\end{array}$ & $\begin{array}{l}-0.0016 \\
(0.0093)\end{array}$ \\
\hline $\begin{array}{l}\text { [more hours]Ten }+ \text { [more } \\
\text { hours]OV.Ten }=0 \\
\text { Prob }>\text { chi } 2\end{array}$ & 0.89 & 0.27 & 0.05 & 0.04 \\
\hline Sample size & 6,260 & 2,725 & 2,709 & 1,232 \\
\hline
\end{tabular}

Notes: Bracketed figures are standard errors and $*^{*}\left({ }^{*}\right)$ denotes $1 \%(5 \%)$ significance. OV is a dummy variable that equals 1 if a worker is working paid overtime, otherwise zero.

Additional controls in the BHPS regressions are (i) levels of pre-work education (five levels from university degree to legal minimum years of schooling), (ii) a dummy denoting whether cohabiting with partner, (iii) dummy denoting whether divorced, (iv) the age of youngest dependent child, and (v) year fixed effects. 
Table 5 Estimates of wage - premium relationship: plant and machine operatives, NESPD, 1991-2011

\begin{tabular}{|l|cc|}
\hline & OLS & $\begin{array}{c}\text { Individual fixed } \\
\text { effects }\end{array}$ \\
\hline AVERAGE PREMIUM & $\begin{array}{c}-0.0290^{* *} \\
(0.0011)\end{array}$ & $\begin{array}{c}-0.0166^{* *} \\
(0.0007)\end{array}$ \\
TENURE & $0.0270^{* *}$ & $0.0164^{* *}$ \\
TENURE ${ }^{2}$ 100 & $(0.0007)$ & $(0.0005)$ \\
AGE & $-0.0950^{* *}$ & $-0.0626^{* *}$ \\
& $(0.0045)$ & $(0.0034)$ \\
AGE ${ }^{2}$ /100 & $0.0470^{* *}$ & $0.0440^{* *}$ \\
& $(0.0006)$ & $(0.0006)$ \\
\hline COLLECTIVE BARGAINING & $-0.0545^{* *}$ & $-0.0488^{* *}$ \\
& $(0.0008)$ & $(0.0008)$ \\
\hline Year dummies & $0.1022^{* *}$ & $0.0323^{* *}$ \\
\hline Industry dummies & $(0.0031)$ & $(0.0024)$ \\
\hline Sample size & & Yes \\
\hline
\end{tabular}

Notes: Dependent variable is log (real basic hourly wage rate). Sample: male plant and machine operatives aged 16 to 65 . Bracketed figures are standard errors and ${ }^{* *}\left({ }^{*}\right)$ denotes $1 \%(5 \%)$ significance. 